\title{
Retraction Note to: Computational studies on the regioselectivity of metal-catalyzed synthesis of $1,2,3$ triazoles via click reaction: a review
}

\author{
Tayebeh Hosseinnejad $^{1} \cdot$ Bahareh Fattahi $^{1} \cdot$ Majid M. Heravi $^{1}$
}

Published online: 7 March 2019

(C) Springer-Verlag GmbH Germany, part of Springer Nature 2019

\author{
Retraction Note to: J Mol Model (2015) 21: 264 \\ https://doi.org/10.1007/s00894-015-2810-2
}

The editor has retracted this article (1) because it contains sections that substantially overlap with a number of previously published sources without appropriate citation and acknowledgment $(2,3,4,5)$. This includes overlap in figures 1 through to 4 between this article (1) and an article published previously by Gold et al (3), figure 15 and 17 in this article and an article published previously by Luo et al (4), and table 1 which appears to be reproduced from (5). Tayebeh Hosseinnejad and Majid M. Heravi do not agree to this retraction. Bahareh Fattahi could not be reached for comment.

1) Tayebeh Hosseinnejad, Bahareh Fattahi, Majid M. Heravi (2015) Computational studies on the regioselectivity of metal-catalyzed synthesis of 1,2,3 triazoles via click reaction: a review https://link. springer.com/article/10.1007/s00894-015-2810-2 (this article)

2) Lal S, Rzepa HS, Díez-González S (2014) Catalytic and Computational Studies of N-Heterocyclic Carbene or Phosphine-Containing Copper(I) Complexes for the
Synthesis of 5-Iodo-1,2,3-Triazoles. ACS Catal 4:22742287. https://doi.org/10.1021/cs500326e

3) Gold B, Shevchenko NE, Bonus N, et al (2012) Selective transition state stabilization via hyperconjugative and conjugative assistance: stereoelectronic concept for copper-free click chemistry. J Org Chem 77:75-89. https://doi.org/10.1021/jo201434w

4) Luo Q, Jia G, Sun J, Lin Z (2014) Theoretical studies on the regioselectivity of iridium-catalyzed 1,3-dipolar azide-alkyne cycloaddition reactions. J Org Chem 79:11970-11980. https://doi.org/10.1021/jo5018348

5) Karthik Kumar K, Mahesh Kumar R, Subramanian V, Mohan Das T (2010) Expedient synthesis of coumarincoupled triazoles via 'click chemistry' leading to the formation of coumarin-triazole-sugar hybrids. Carbohydr Res 345:2297-2304. https://doi.org/10.1016/j.carres. 2010.07.037

Publisher's note Springer Nature remains neutral with regard to jurisdictional claims in published maps and institutional affiliations.

The online version of the original article can be found at https://doi.org/ $10.1007 / \mathrm{s} 00894-015-2810-2$

Majid M. Heravi

mmh1331@yahoo.com

1 Department of Chemistry, Alzahra University, Vanak, Tehran, Iran 